\title{
Ramos do arco aórtico e da aorta torácica em bicho-preguiça (Bradypus variegatus)
}

\author{
[Branches of the aortic arch and thoracic aorta of the sloth (Bradypus variegatus)] \\ P.V. Albuquerque ${ }^{1}$, D.G.F. Sena ${ }^{1}$, R.S. Braz ${ }^{1}$, E.P. Mesquita ${ }^{1}$, M.A.S. Lacerda $^{2}$,
W.J. Silva ${ }^{1}$, F.B. Sá ${ }^{1}$, M.J.A.A.L. Amorim \\ ${ }^{1}$ Universidade Federal Rural de Pernambuco - Recife, PE \\ ${ }^{2}$ Área de Radiologia - Clínica Veterinária Pet Dream - Recife, PE
}

\begin{abstract}
RESUMO
As preguiças são mamíferos arborícolas, bem específicos quanto aos hábitos e à morfofisiologia. Essa condição faz delas ainda mais vulneráveis aos impactos ambientais. Com o objetivo de fornecer informações que auxiliem na clínica médico-cirúrgica desses Xenarthras, realizou-se um estudo do arco aórtico e da artéria aorta torácica, a fim de se identificarem seus principais ramos. Foram utilizados 10 animais da espécie Bradypus variegatus, sendo uma fêmea e três machos submetidos a dissecação, por meio da qual foram obtidas medidas de diâmetro e comprimento dos vasos, enquanto três fêmeas e três machos destinaram-se à técnica de radiografia digital com contraste. Constatou-se uma sintopia uniforme do arco, bem como da porção descendente da artéria aorta no tórax. No entanto, a topografia difere consideravelmente. Com base nos ramos, percebeu-se, independentemente do sexo, uma maior variação naqueles originados do arco e dos que emergem da artéria aorta torácica e irrigam estruturas medianas e do antímero direito do tórax. Foram obtidos valores maiores para o diâmetro das artérias na fêmea do que nos machos e, para o comprimento da artéria aorta torácica, foram encontrados valores correspondentes em ambos. Toda essa variação dos bradipodídeos apresenta diferenças em relação a outros mamíferos.
\end{abstract}

Palavras-chave: pilosa, Bradypus variegatus, angiologia, aorta

\begin{abstract}
Sloths are arboreal mammals, very specific, regarding their habits and morphology. This condition makes them even more vulnerable to environmental impacts. In order to provide information to assist in the medical and surgical assistance to these Xenarthras, a study of the aortic arch and thoracic portion of the descending aorta was carried out with the purpose of identify its main branches. Ten animals of the Bradypus variegatus species were used. One female and three males were submitted to dissection, where measurements of vessel diameter and length were obtained, while three females and three males were submitted to the digital contrast $x$-ray technique. There was a uniform syntopy of the arch, as well as of the descending portion of the aorta in the thorax. However, the topography differs considerably. Based on the branches, regardless of gender, a greater variation was observed in those originating from the arch, and those that emerge from the thoracic aorta and irrigate medial structures and the right antimere of the thorax. Greater values were obtained for the diameter of the arteries in the female than in the males and corresponding values for the length of the thoracic aorta in both. All this variation is possibly related to the adaptive processes of Bradipodidae over time.
\end{abstract}

Keywords: pilosa, Bradypus variegatus, angiology, aorta

\section{INTRODUÇÃO}

Os bichos-preguiça são mamíferos arborícolas, com hábito e morfofisiologia muito peculiares (Peres, 2005; Ramos, 2006). Estão divididos em dois gêneros, Bradypus e Choloepus.

Recebido em 21 de abril de 2017

Aceito em 27 de setembro de 2017

* Autor para correspondência (corresponding author)

E-mail: priscilla2009w@ hotmail.com
Representam a superordem Xenarthra, juntamente com os tamanduás e tatus (Gardner, 2005).

Os bradipodídeos estão distribuídos da América Central até o norte da Argentina, tendo uma ampla ocorrência no Brasil. Todavia, a 
devastação de seu habitat tem gerado um impacto significativo nas populações (Azarias et al., 2006). O homem vem adentrando as áreas de floresta, o que tem provocado, sobretudo, a fragmentação de ambientes naturais e aumentado, consequentemente, as taxas de extinção (Primack e Rodrigues, 2001).

Entre os mamíferos, a preguiça é considerada o caso mais curioso de convergência adaptativa (Gaudin, 2004) e sua filogenia não está completamente definida (Pereira Júnior, 2007). Assim como os demais Xenarthras, esses bichos lentos evoluíram praticamente isolados dos demais eutérios, após a separação da Gondwana. Sofreram grandes modificações adaptativas na passagem das formas gigantes terrícolas para a conformação corpórea atual, com um tamanho reduzido e uma vida praticamente restrita à copa das árvores (Bergqvist et al., 2000).

Muitos dos aspectos anatômicos das preguiças são conhecidos e apresentam grandes particularidades, no entanto existem ainda várias lacunas a serem preenchidas. Nesse contexto, propôs-se identificar as características e ramificações do arco aórtico e da artéria (a.) aorta torácica na espécie Bradypus variegatus, a fim de agregar conhecimentos acerca do sistema cardiovascular, que tenham aplicabilidade na clínica médico-cirúrgica desses animais.

\section{MATERIAL E MÉTODOS}

Neste estudo, utilizaram-se 10 cadáveres de bichos-preguiça $B$. variegatus. Quatro deles (uma fêmea adulta e três machos adultos) pertencem ao acervo da Área de Anatomia do Departamento de Morfologia e Fisiologia Animal da Universidade Federal Rural de Pernambuco DMFA/UFRPE e foram destinados à dissecação. Os seis restantes (três fêmeas adultas e três machos adultos) foram recebidos do Zoológico de Dois Irmãos, após morte natural, e submetidos à técnica de radiografia digital com contraste. Os procedimentos realizaram-se sob autorização do Comitê de Ética de Uso e Experimentação Animal no 080/2016 e Sisbio $n^{\circ}$ 46665-3.

Os animais destinados à dissecação foram fixados por meio da canulação da a. carótida comum esquerda com formaldeído a $20 \%$ e mantidos em tanque de solução salina a $30 \%$.
Realizou-se uma incisão sagital mediana no pescoço e no tórax, seguida do rebatimento da pele, da musculatura, das costelas e do pulmão esquerdo, a fim de se ter acesso à a. aorta e a seus ramos, que foram minuciosamente dissecados e identificados. Uma vez feitos, obtiveram-se a sintopia, a topografia e o diâmetro do arco e de seus ramos principais. Para as medições de todos esses diâmetros e do comprimento da a. aorta torácica, utilizou-se paquímetro de aço $(150 \mathrm{~mm} / 0,02 \mathrm{~mm})$. Tais etapas realizaram-se no Laboratório de Anatomia do DMFA-UFRPE. Posteriormente, calculou-se a porcentagem de ocorrência dos vasos nos espécimes e a média e desvio-padrão de seus diâmetros, quando necessário. Foram obtidas fotografias a partir de câmera digital Canon Powershot Sx400is, para análise dos resultados.

Os cadáveres de bichos-preguiça submetidos à técnica de radiografia digital com contraste foram fixados em formaldeído a $5 \%$ a partir da canulação da a. carótida comum esquerda e, em seguida, injetou-se solução líquida de bário e gelatina incolor dissolvida em água e aquecida. Poucas horas após a injeção do contraste, os animais foram submetidos à radiografia digital, em uma clínica veterinária, em aparelho Kodak, ajuste de $60 \mathrm{kV}$ e $160 \mathrm{~mA}$, tempo 0,125 segundo, distância do foco e filme $95 \mathrm{~cm}$, processamento e CR modelo 140. Os filmes obtidos foram averiguados para determinação dos ramos aórticos.

Para fins de nomenclatura, utilizou-se a Nomina Anatômica Veterinária (International Committee on Veterinary Gross Anatomical Nomenclature, 2012).

\section{RESULTADOS}

Com base nas análises da a. aorta torácica do bicho-preguiça, observou-se que esta emerge do coração e curva-se para a esquerda, originando o arco aórtico, e segue pelo tórax até adentrar ao diafragma, no hiato aórtico. Na região do arco, faz sintopia dorsalmente com a veia cava cranial, a traqueia e o esôfago, ventral e cranialmente com o pulmão esquerdo e caudalmente com a aurícula esquerda, enquanto ao longo de seu trajeto descendente no tórax, a artéria relacionase em sua porção inicial, dorsalmente com a traqueia e o esôfago, ventrolateralmente no antímero esquerdo com pulmão esquerdo e no 
antímero direito com o corpo das vértebras torácicas. Em sua região média e caudal, liga-se dorsalmente com as costelas, seguindo as demais relações de sua fração inicial.

O arco aórtico apresentou topografias distintas, originando-se ao nível da vértebra torácica número 4 (T4) e continuando com a aorta torácica ao nível de T5 em $100 \%$ das fêmeas e em 50\% dos machos; estende-se de T3-T4, T5T6 e T6-T7 em $\cong 16,7 \%$ dos machos. Foi obtido, para os espécimes dissecados, um valor de $9 \mathrm{~mm}$ para o diâmetro do ápice do arco na fêmea e uma variação de $6,5 \mathrm{~mm}$ a $7,7 \mathrm{~mm}$ nos machos.

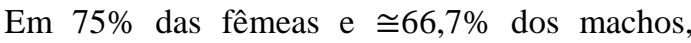
emergem três ramos, o tronco braquiocefálico direito, a carótida comum esquerda e a. subclávia

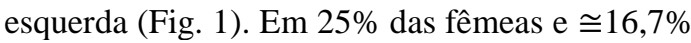
dos machos, originam-se dois ramos, um tronco comum ao tronco braquiocefálico direito e a carótida comum esquerda, e um outro ramo, a subclávia esquerda (Fig. 2). E em $\cong 16,7 \%$ dos machos, observou-se um único ramo, o tronco bibraquiocefálico (Fig. 3).

Nos animais em que do arco emergem três ramos, o tronco braquiocefálico direito origina-se ventral à traqueia, tornando-se lateral direito a esta e, ao nível de T1, bifurca-se na a. carótida comum direita e a. subclávia direita. Nas preguiças em que foram visualizados dois ramos do arco, o tronco braquiocefálico direito e o carotídeo comum esquerdo posicionam-se ventralmente ao esôfago e, na altura de T3, bifurcam-se em tronco braquiocefálico direito e a. carótida comum esquerda; o tronco braquiocefálico direito cruza a traqueia ventralmente e, logo após sua emissão, torna-se lateral direito e em T1 se bifurca em a. carótida comum direita e a. subclávia direita. No espécime em que se visualizou apenas um ramo do arco, há um tronco bibraquiocefálico, que se origina ventralmente ao esôfago e se bifurca, ao nível de T3, em tronco braquiocefálico direito, que cruza a traqueia ventralmente, tornando-se lateral direito ao órgão e se bifurca em a. carótida comum direita e a. subclávia direita na altura de $\mathrm{T} 1$, e tronco braquiocefálico esquerdo que, após a origem, cruza o esôfago, torna-se lateral esquerdo a este e se bifurca, ao nível de T2, em a. carótida comum esquerda e a. subclávia esquerda.

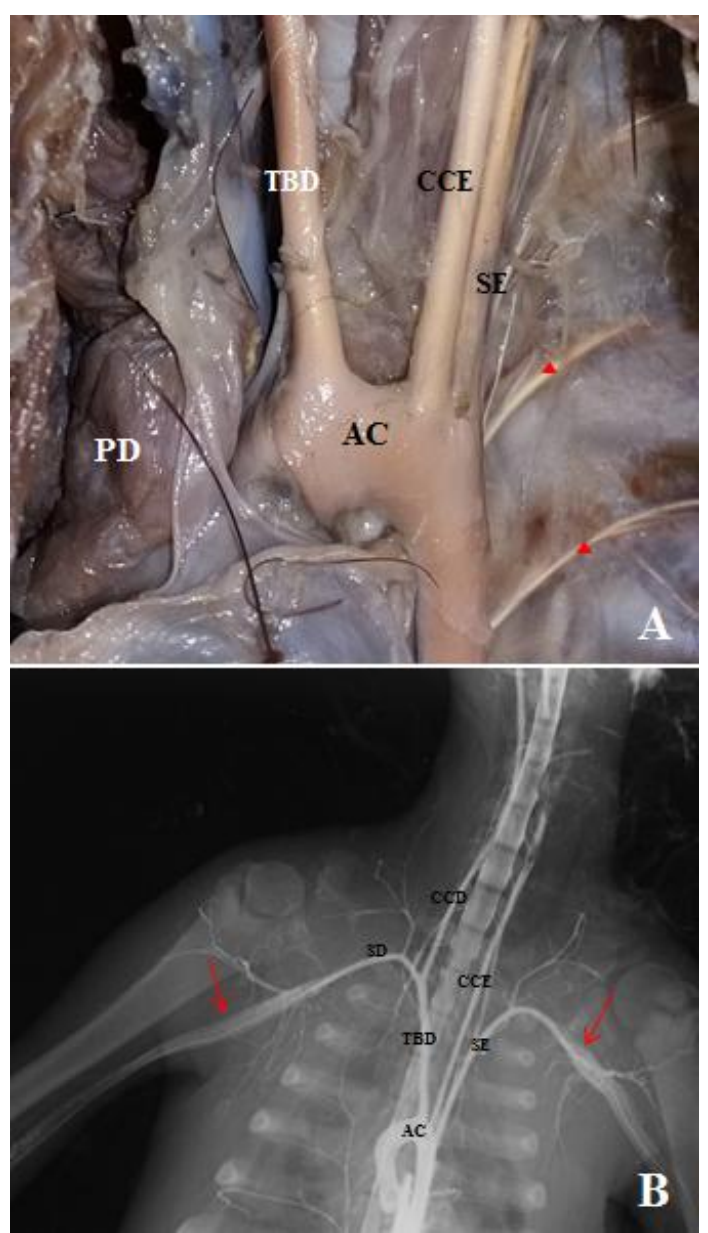

Figura 1. Emissão de três ramos do arco aórtico (AC) em preguiças adultas. A. Fotomacrografia após dissecação dos vasos. B. Radiografia digital com contraste do tórax. Tronco braquiocefálico direito (TBD), artéria carótida comum esquerda (CCE), artéria carótida comum direita (CCD), artéria subclávia esquerda (SE), artéria subclávia direita (SD), artérias intercostais dorsais esquerdas (triângulo vermelho), redes admiráveis $(\rightarrow)$, pulmão direito (PD).

Em todos os espécimes, a a. carótida comum direita emerge numa posição lateral direita à traqueia, mas logo se torna dorsal, seguindo, assim, até sua bifurcação em a. carótida externa direita e a. carótida interna direita. A a. carótida comum esquerda origina-se ventralmente ao esôfago, mas passa a ser lateral esquerda a este órgão até a bifurcação em a. carótida externa esquerda e a. carótida interna esquerda. Para ambas as artérias (aa.) carótidas comuns, a bifurcação se dá na altura do primeiro anel traqueal. As aa. subclávias, direita e esquerda, 
após suas emissões, adentram em direção às respectivas cinturas escapulares e originam uma rede admirável, que segue irrigando os membros torácicos.

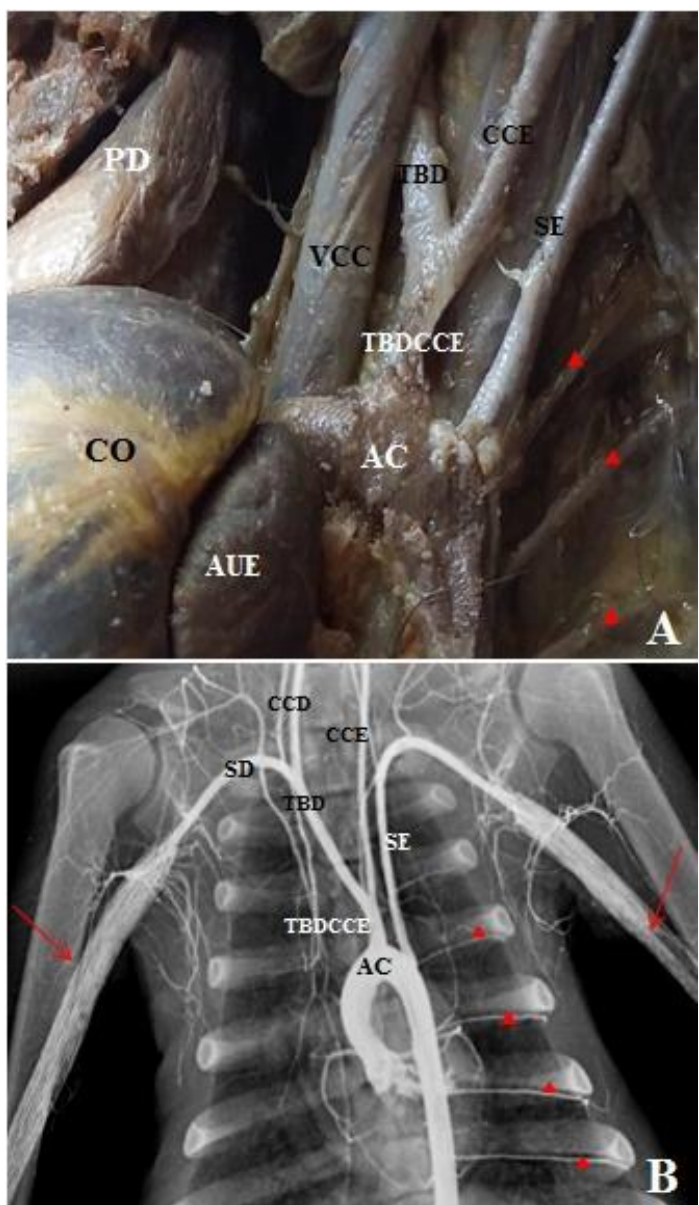

Figura 2. Emissão de dois ramos do arco aórtico (AC) em preguiças adultas. A. Fotomacrografia após dissecação dos vasos. B. Radiografia digital com contraste do tórax. Tronco braquiocefálico direito e carotídeo comum esquerdo (TBDCCE), tronco braquiocefálico direito (TBD), artéria carótida comum esquerda (CCE), artéria carótida comum direita (CCD), artéria subclávia esquerda (SE), artéria subclávia direita (SD), artérias intercostais dorsais esquerdas (triângulo vermelho), redes admiráveis $(\rightarrow)$, veia cava cranial (VCC), coração (CO), aurícula esquerda (AUE), pulmão direito (PD).

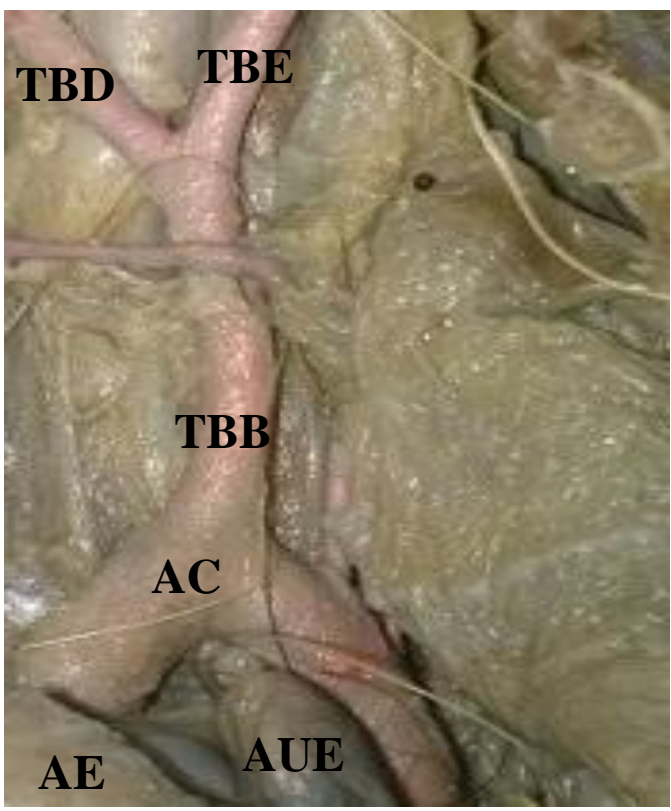

Figura 3. Emissão de um ramo do arco aórtico (AC) em preguiça adulta. Tronco bibraquiocefálico (TBB), tronco braquiocefálico direito (TBD), tronco braquiocefálico esquerdo (TBE), átrio esquerdo (AE), aurícula esquerda (AUE).

$\mathrm{Na}$ Tab. 1, consta o diâmetro das artérias originadas do arco, nos espécimes que foram dissecados, medido imediatamente após a origem dos vasos. Pode-se perceber que os ramos arteriais comuns, para ambos os sexos, com exceção da a. carótida comum direita, possuem diâmetro maior na fêmea.

A a. aorta descendente torácica apresenta, em sua extensão, assim como o arco, uma esqueletopia

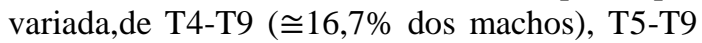
(25\% das fêmeas e $\cong 16,7 \%$ dos machos), T5T10 (75\% das fêmeas e $\cong 33,3 \%$ dos machos), T6-T11 (@16,7\% dos machos) e T7-T11

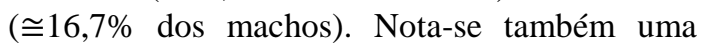
diferença no diâmetro do vaso da fêmea dissecada em relação aos machos, tanto na porção inicial quanto na altura do hiato aórtico, sendo de 7,8mm imediatamente após o arco e de $6,7 \mathrm{~mm}$ nas proximidades do diafragma para a fêmea e variando de $6,1 \mathrm{~mm}$ a $6,6 \mathrm{~mm}$ e de $5,1 \mathrm{~mm}$ a $5,6 \mathrm{~mm}$ nos machos, bem como no comprimento, sendo de $7,61 \mathrm{~cm}$ na fêmea e de $7,41 \mathrm{~cm}$ a $7,76 \mathrm{~cm}$ nos machos. 
Tabela 1. Diâmetro dos ramos do arco aórtico, medidos imediatamente após a origem dos vasos, em bichos-preguiça Bradypus variegatus adultos dissecados

\begin{tabular}{|c|c|c|}
\hline \multirow{2}{*}{ Ramos do arco aórtico } & \multicolumn{2}{|c|}{ Diâmetro (mm) } \\
\hline & Fêmea & Macho \\
\hline Tronco braquiocefálico direito & 5 & 3 a $4.9 *$ \\
\hline Tronco braquiocefálico esquerdo & - & 3.4 \\
\hline Tronco bibraquiocefálico & - & 4.4 \\
\hline Artéria carótida comum direita & 2.5 & 2.4 a $3.1 *$ \\
\hline Artéria carótida comum esquerda & 3.1 & 2.5 a $2.9 *$ \\
\hline Artéria subclávia direita & 3.1 & 2.3 a $2.7 *$ \\
\hline Artéria subclávia esquerda & 3.3 & 2.4 a $2.8^{*}$ \\
\hline $\begin{array}{l}\text { Tronco braquiocefálico direito e } \\
\text { carotídeo comum esquerdo }\end{array}$ & - & 3.5 \\
\hline
\end{tabular}

- Indica que o animal não possui o ramo arterial.

* Indica que o ramo foi encontrado em mais de um animal, constando o maior e o menor diâmetro obtido.

Ao longo de seu trajeto descendente pelo tórax, a a. aorta emite as aa. intercostais dorsais esquerdas, ao nível das vértebras torácicas, que se inserem na parede do tórax no antímero esquerdo (Fig. 1, 2, 4 e 5).

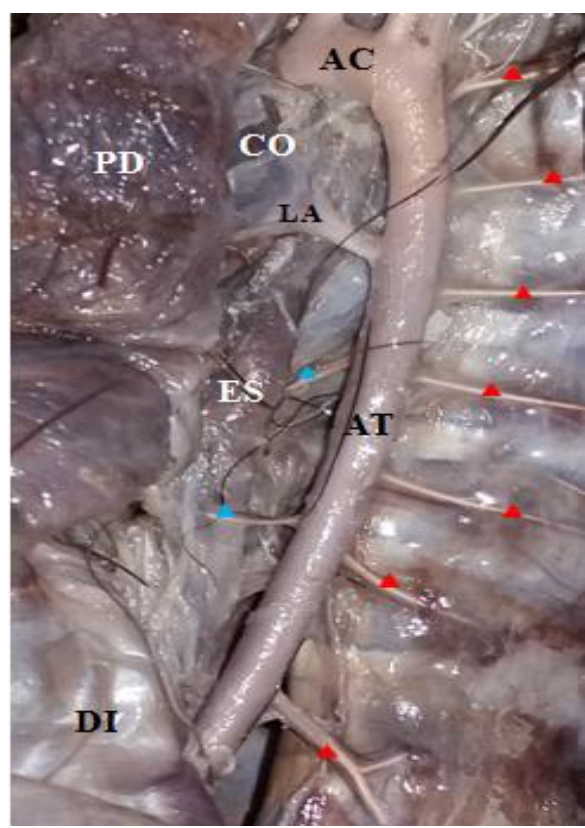

Figura 4. Identificação do ligamento arterioso (LA) e dos ramos da artéria aorta torácica (AT) em preguiça adulta. Arco aórtico (AC), artérias intercostais dorsais esquerdas (triângulo vermelho), ramos aórticos que irrigam o antímero direito do tórax (triângulo azul), o coração (CO), o pulmão direito (PD), o esôfago (ES) e o diafragma (DI).
As aa. intercostais dorsais direitas emergem das porções média e final da a. aorta torácica e, em número bem reduzido em relação às esquerdas, seguem atravessando ventralmente o corpo das vértebras torácicas até atingirem a parede do tórax no antímero direito. Em $25 \%$ das fêmeas e em $50 \%$ dos machos, uma dessas artérias emite um ramo pulmonar direito. Na região mais caudal, afloram ramos que atravessam o corpo das vértebras torácicas e irrigam estruturas do antímero direito do tórax, o ramo broncoesofágico em $\cong 8,3 \%$ dos machos, o pulmonar direito em $25 \%$ das fêmeas e $\cong 16,7 \%$ dos machos, esofágico (50\% das fêmeas) e diafragmático (25\% das fêmeas) (Fig. 4 e 5). Constatou-se ainda a saída de um ramo colateral de uma a. intercostal dorsal esquerda, que segue para o antímero direito, inserindo-se na parede torácica ( $25 \%$ das fêmeas), e um ramo intercostal

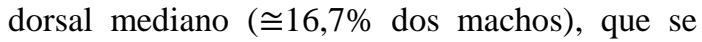
situa ventralmente ao corpo vertebral (Fig. 5). O ligamento arterioso foi visualizado ligando externamente a a. aorta ao tronco pulmonar no início da a. aorta torácica (Fig. 4).

Com base no diâmetro da origem dos ramos da a. aorta torácica, conseguido por meio dos animais dissecados, obteve-se um valor, em média, maior na fêmea $(1,73 \pm 0,53 \mathrm{~mm})$ do que nos machos $(1,08 \pm 0,11 \mathrm{~mm})$. 

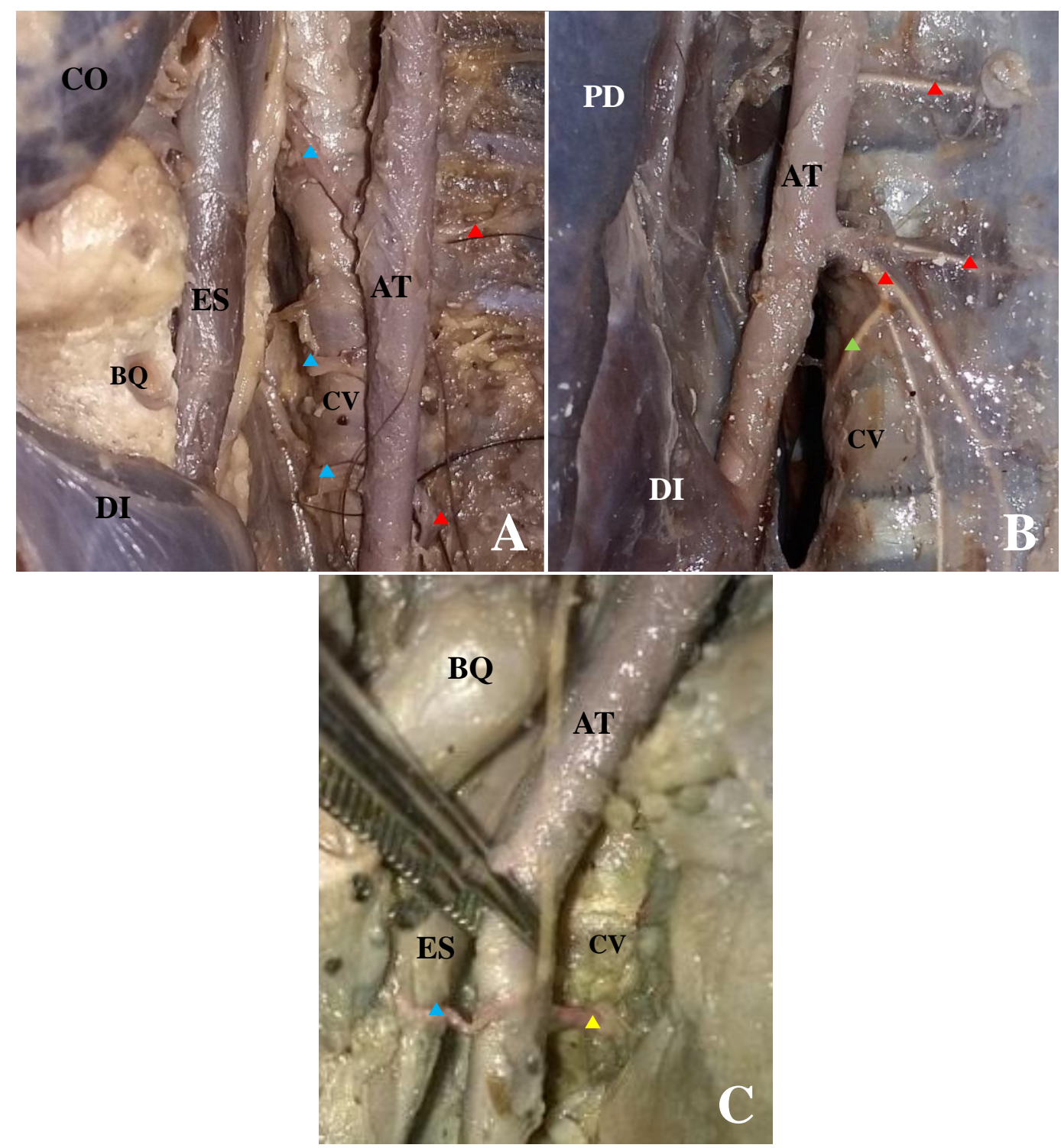

Figura 5. Identificação de ramos aórticos descendentes que irrigam o antímero direito do tórax (triângulo azul), em preguiças adultas. A. B. C. Fotomacrografia após dissecação dos vasos. Artéria aorta torácica (AT), ramo colateral de uma artéria intercostal dorsal esquerda (triângulo verde), ramo intercostal dorsal mediano (triângulo amarelo), artérias intercostais dorsais esquerdas (triângulo vermelho), coração $(\mathrm{CO})$, pulmão direito (PD), brônquio (BQ), esôfago (ES), diafragma (DI), corpo vertebral (CV).

\section{DISCUSSÃO}

Não foram encontrados relatos sobre a descrição anatômica do arranjo dos ramos colaterais do arco aórtico e da a. aorta torácica, bem como nenhum estudo morfométrico desses vasos em $B$. variegatus. Assim, utilizaram-se, como referências para a discussão deste trabalho, informações anatômicas existentes para outros animais.
Segundo Santos et al. (2004), a origem e a disposição dos ramos arteriais colaterais que emergem do arco aórtico, nos mamíferos, de modo geral, possuem grandes variações.

O trajeto do arco nas preguiças é voltado para o antímero esquerdo, concordando com os achados de Oliveira et al. (2015), em suas pesquisas utilizando 20 preás (Galea spixii) para descrição dos ramos aórticos na espécie. 
A predominância do arranjo dos ramos colaterais do arco, em $75 \%$ das fêmeas e em $\cong 66,7 \%$ dos machos de B. variegatus, coincidiu com $6,7 \%$ dos arcos aórticos da chinchila, analisados por Araújo et al. (2004), com a disposição de tronco braquiocefálico direito, a. carótida comum esquerda e a. subclávia esquerda. Tal característica foi também observada em 13,4\% dos coelhos (Oryctolagus cuniculus) estudados por Souza et al. (2013).

Este perfil de ramificação, com a emissão do tronco braquiocefálico, da a. carótida comum esquerda e da a. artéria subclávia esquerda, é comum na anatomia veterinária (Schwarze e Schröder, 1970).

Em $25 \%$ das fêmeas e em $\cong 16,7 \%$ dos machos de bichos-preguiça, evidenciou-se, como ramos colaterais do arco, o tronco braquiocefálico direito e carotídeo comum esquerdo e a. subclávia esquerda, como descrito por Araújo et al. (2004) em 93,3\% das chinchilas utilizadas pelos autores.

Em estudo realizado por Reckziegel et al. (2003), em 28 gambás (Didelphis albiventris) os autores perceberam que, para $39,29 \%$ dos animais, do arco emergiu o tronco braquiocefálico, de onde se ramificaram a a. subclávia direita e o tronco bicarotídeo, cuja bifurcação originou as a. carótidas comuns direita e esquerda. Essa condição foi também proposta por Machado et al. (2010), para 15 exemplares de Saruê (Didelphis marsupialis), e difere das conformações visualizadas nas preguiças.

Nos bradipodídeos em que foram visualizados dois ramos do arco, o tronco braquiocefálico direito e o carotídeo comum esquerdo posicionam-se ventralmente ao esôfago. $\mathrm{Na}$ espécie canina, Getty (1981) descreve a a. carótida comum esquerda como o primeiro ramo proveniente desse tronco.

O achado de um tronco bibraquiocefálico, neste trabalho, coincide, em parte, com o relato de Domeniconi et al. (2004) em tatu-galinha (Dasypus Novemcinctus), que indicam a origem de dois troncos braquiocefálicos, um direito e um esquerdo, advindos do arco aórtico, todavia de maneira independente.
Culau et al. (2007) identificaram apenas um ramo colateral do arco, o tronco braquiocefálico, em capivara (Hydrochoerus hydrochaeris). Pinheiro et al. (2012) descreveram apenas uma a. braquiocefálica, no tamanduá-mirim (Tamandua tetradactyla), da qual ocorre a emissão de ramos.

Nas artérias que surgem do arco, a localização topográfica da emergência próxima a órgãos específicos pode interferir e desviar os vasos, como ocorre nas preguiças, com o tronco braquiocefálico direito, que sofre desvio lateral direito em decorrência da posição da traqueia, e o braquiocefálico esquerdo, com um desvio lateral esquerdo, mediante o esôfago. $\mathrm{O}$ tronco braquiocefálico em carnívoros se ramifica do arco aórtico, dirigindo-se cranialmente e percorrendo um trajeto ventral a traqueia (Bruni e Zimmerl, 1977).

Nos espécimes analisados de B. variegatus, em todos, a a. carótida comum direita emerge numa posição lateral direita à traqueia, mas logo se torna dorsal, seguindo assim até sua bifurcação em a. carótida externa direita e a. carótida interna direita. A a. carótida comum esquerda origina-se ventralmente ao esôfago, mas logo passa a ocupar uma posição lateral esquerda.

No entanto, nas capivaras estudadas por Culau et al. (2007), em 28,6\%, o tronco braquiocefálico originou-se da a. subclávia esquerda; esta se trifurcou em a. subclávia direita, a. carótida comum direita e esquerda.

Há relatos quanto à presença de tronco bicarotídeo surgindo direto da a. aorta, em cachorro-do-mato (Cerdocyon thous) (Lima et al., 2016), e das aa. carótidas comuns emergindo da a. subclávia esquerda em quatro dos 28 espécimes $(14,28 \%)$ de gambá (Didelphis albiventris) analisados por Reckziegel et al. (2003). A ausência de tronco braquiocefálico não foi descrita nos exemplares de B. variegatus, tal como não foi evidenciada por Araújo et al. (2004), em 30 espécimes de Chinchilla lanígera, nem por Souza et al. (1996), em sete tatus-peba (Euphractus sexcinctus).

As aa. subclávias, direita e esquerda, após suas emissões, adentram em direção às respectivas cinturas escapulares e originam uma rede admirável que seguem irrigando os membros torácicos. Em seu estudo, Martins et al. (2010), 
em um espécime de Leopardus pardalis, descreveram a origem da a. subclávia esquerda e seu trajeto oblíquo na superfície ventral do esôfago.

A a. aorta torácica variou em B. variegatus quanto à esqueletopia e espessura entre machos e fêmeas. Durante seu trajeto, ocorre a emissão de ramos intercostais dorsais e viscerais, em alguns casos, em pouca quantidade, o que não gera nenhuma problemática, tendo em vista que, segundo Biihrer et al. (2015), as aa. subclávias direita e esquerda continuam seu percurso em direção aos membros torácicos, mas emitem também ramos para a irrigação do tórax.

As aa. intercostais dorsais esquerdas surgem ao nível das vértebras torácicas, passando a irrigar a parede dessa cavidade no antímero esquerdo. Já as aa. intercostais dorsais direitas emergem das porções média e final da a. aorta torácica e seguem atravessando ventralmente o corpo das vértebras até atingirem a parede do tórax, no antímero direito. Essa descrição da topografia encontrada nas preguiças, bem como a presença de ramos viscerais da aorta no tórax, também foi relatada por Biihrer et al. (2015), que descrevem, em dois exemplares de quati (Nasua nasua), a a. aorta descendente. Desta se ramificam as artérias broncoesofágica, intercostais dorsais e costoabdominal dorsal.

Em B. variegatus, constatou-se a existência do ramo pulmonar direito e de outros ramos que afloram diretamente da a. aorta ou das aa. intercostais dorsais e atravessam o corpo das vértebras torácicas, como os ramos broncoesofágico, esofágico e diafragmático. Essa ramificação foi descrita também por Dyce et al. (2010), que afirmam que as aa. broncoesofágicas e as aa. intercostais dorsais são ramos diretos da a. aorta descendente em animais domésticos.

A morfometria dos vasos sadios provenientes da a. aorta no tórax é rara na literatura. Todavia, obtiveram-se diâmetros maiores do arco aórtico nas preguiças do que em $17,53 \%$ dos fetos humanos dissecados por Sá Filho et al. (2016).

Os ramos colaterais do arco aórtico e da a. aorta torácica em $B$. variegatus sofrem variações em relação a outras espécies, sejam elas domésticas ou silvestres, o que possivelmente, relaciona-se aos eventos adaptativos a que estiveram e estão submetidas as preguiças.

\section{CONCLUSÃO}

Em B. variegatus, constatou-se uma sintopia uniforme do arco aórtico, bem como da a. aorta torácica. No entanto, a topografia varia consideravelmente, podendo-se atribuir essa condição ao fato de os bradipodídeos apresentarem uma variação no número de vértebras cervicais. Com base nos ramos, percebeu-se, independentemente do sexo, uma maior variação naqueles originados do arco e naqueles que emergem da a. aorta torácica e irrigam estruturas medianas e do antímero direito do tórax. Foram encontrados valores maiores para o diâmetro dos vasos na fêmea do que nos machos, bem como valores correspondentes para o comprimento da a. aorta torácica em ambos.

\section{AGRADECIMENTOS}

À área de Anatomia do Departamento de Morfologia e Fisiologia Animal da Universidade Federal Rural de Pernambuco, Recife-PE, pela disponibilidade do acervo de bichos-preguiça; ao Zoológico de Dois Irmãos, Recife-PE, pela doação de cadáveres de $B$. variegatus e à clínica veterinária Pet Dream, Recife-PE, pela realização das radiografias digitais com contraste nos animais.

\section{REFERÊNCIAS}

ARAÚJO, A.C.P.; OLIVEIRA, J.C.D.; CAMPOS, R. Ramos colaterais do arco aórtico e suas principais ramificações em chinchila (Chinchilla lanígera). Rev. Port. Ciênc.Vet., v.99, p.53-58, 2004.

AZARIAS, R.E.G.R.; AMBRÓSIO, C.E.; MARTINS, D.S. et al. Estrutura morfológica dos dentes do bicho preguiça de coleira (Bradypus torquatus). Illiger, 1858. Biotemas, v.19, p.73-84, 2006.

BERGQVIST, L.P.; ABUHID, V.S.; DEL GIUDICEG, G.M. Mamíferos. In: CARVALHO, I.S. Paleontologia. Rio de Janeiro: Interciência, 2000. cap.32, p.595-623.

BIIHRER, D.A.; GUIMARÃES, G.C.; LOPES, G.C.; LIMA, I.G. Descrição anatômica dos ramos arteriais da aorta torácica e abdominal do quati (Nasua nasua) (Carnivora, Procyonidae). Biotemas, v.28, p.119-124, 2015. 
BRUNI A.C.; ZIMMERL, V. Anatomia degli animale domestici. Milano: Casa Editrici Dr. Francesco Vallardi., p.30-37, 1977.

CULAU, P.O.V.; RECKZIEGEL, S.H.; LINDEMANN, T. et al. Colaterais do arco aórtico da capivara (Hydrochoerus hydrochaeris). Acta Sci. Vet., p.89-92, 2007.

DYCE，K.M.; SACK，W.O.; WENSING，C.J.G. Tratado de anatomia veterinária. 4.ed. Rio de Janeiro: Guanabara Koogan, 2010. 834p.

DOMENICONI, R.F.; ABREU, M.A.F.; BENETTI, E.J.; VILAÇA, J.S. The contribution of the aortic branches in the vascularization of cervical regions, during the development of the nine bandeds armadillo (Dasypus Novemcinctus, L. 1758). Int. J. Morphol., v.22, p.113-118, 2004.

GARDNER, A.L. Order Pilosa. In: WILSON, D.E.; REEDER, D.M. (Eds.). Mammal species of the world. Baltimore: Johns Hopkins University Press, 2005. v.1, p.100-103.

GAUDIN, T.J. Phylogenetic relationships among sloths (Mammalia, Xenarthra, Tardigrada): the craniodental evidence. Zool. J. Linnean Soc., n.140, p.255-305, 2004.

GETTY, R. Anatomia dos animais domésticos. Rio de Janeiro: Guanabara Koogan, 1981. v.2, 460p.

LIMA, A.R.; SOUZA, D.C.; CARMO, D. et al. Ramos colaterais do arco aórtico e suas principais ramificações no cachorro-do-mato (Cerdocyon thous). Pesqui. Vet. Bras., v.36, p.647-651, 2016.

MACHADO, M.R.F.; REIS, A.C.G.; MARTINS, L.L. et al. Arco aórtico do Saruê (Didelphis marsupialis Linnaeus, 1758). PUBVET, v.4, 869art., 2010.

MARTINS, D.M.; LIMA, A.R.; PINHEIRO, L.L. Descrição morfológica dos ramos colaterais do arco aórtico e suas principais ramificações em Leopardus pardalis. Acta Vet. Brasilica, v.4, p.74-77, 2010.

OLIVEIRA, R.E.M.; OLIVEIRA, G.B.; BARBOSA, P.M.L. Ramos colaterais do arco aórtico do preá (Galea spixii Wagler, 1831). Pesqui. Vet. Bras., v.35, p.762-766, 2015.

PEREIRA, H.R.J. Evolução cromossômica na ordem Xenarthra. 2007. 181f. Tese (Doutorado em Genética) - Programa de Pós-Graduação em Ciências Biológicas, Instituto de Biociências de Botucatu, Universidade Estadual Paulista, São Paulo, SP.
PERES, M.A. Colheita e avaliação do sêmen do bicho-preguiça (Bradypus sp.). 2005. 74f. Dissertação (Mestrado) - Programa de Pós-Graduação em Anatomia dos Animais Domésticos e Silvestres, Faculdade de Medicina Veterinária e Zootecnia, Universidade de São Paulo, São Paulo, SP.

PINHEIRO, V.L.C.; LIMA, A.R.; PEREIRA, L.C. et al. Descrição anatômica dos ramos colaterais do arco aórtico do tamanduá-mirim (Tamandua tetradactyla). Biotemas, v.25, p.133-137, 2012.

PRIMACK, R.B.; RODRIGUES, E. Biologia da conservação. Londrina: [s.n.], 2001. 100p.

RAMOS, F.F. Perfil hematimétrico e identificação da hemoglobina do bicho-preguiça (Bradypus variegatus). 2006. 82f. Dissertação (Mestrado em Fisiolofia) - Programa de Pós-Graduação em Ciências Biológicas, Universidade Federal de Pernambuco, Recife, PE.

RECKZIEGEL, S.H.; LINDEMAN, T.; CULAU, P.O.V.; Colaterais do arco aórtico no gambá (Didelphis albiventris). Ciênc. Rural, v.33, p.507-511, 2003.

SÁ FILHO, A.C.; NASCIMENTO, G.A.; ARAGÃO, J.A. Medidas morfométricas do arco da aorta e seus respectivos ramos. Rev. Saúde Ciênc. Online, v.5, Supl., 12p., 2016.

SANTOS, A.L.Q.; MORAES, F.M.; MALTA, T.S.; CARVALHO, S.F.M.; ALVES JUNIOR, J.R.F. Topografia dos colaterais calibrosos do arco aórtico de um cão - pelada (Procyon cancrivorus - Gray, 1865) (Carnivora - Procyoniadae). Arch. Vet. Sci., v.9, p.6772, 2004.

SCHWARZE E.; SCHRODER L. Compêndio de anatomia veterinária. Zaragoza: Acribia, 1970. p.3334.

SOUZA, F.; BAVARESCO, A.Z.; CAMPOS, R. Ramos colaterais do arco aórtico e suas principais ramificações em coelho da raça Nova Zelândia (Oryctolagus cuniculus). Ciênc. Rural, v.43, p.2261$2267,2013$.

SOUZA, W.M.; CARVALHAL, R.; SOUZA, N.T.M. et al. Ramos do arco da aorta no tatu peba (Euphractus sexcinctus). Vet. Notícias, v.2, p.25-30, 1996. 